\title{
La guerra de los moriscos vista desde una plaza fronteriza
}

\section{(Extractos de las actas capitulares de Quesada)}

(Continuación.)

"Los dichos señores dixeron que por quanto por parte de Francisco Amador e ansí otros labradores del Canpo Cuenca se les á pedido que pongan guarda en el canpo Cuenca, y para ello se nonbren cinquenta honbres peones y ocho de caballo, para que estén en guarda del dicho canpo, y se les de en cada vn mes a cada vno ducado y medio al peón y al de caballo treynta rreales. $\mathrm{Y}$ con esta costa corran los vecinos desta villa, y se reparta entre ellos, a dispusición del concejo, y con los labradores del Canpo Cuenca, y los demande aquellas labores y les den los mantenimientos necesarios".

En 30 de octubre de 1569, "dixeron que por quanto esta villa de Quesada estã ; muy frontera del rreyno de Granada, y cada día los moros corren la tierra y término desta villa, y se llevan los xpitianos de la dicha villa cabtivos, y los ganados del término della, acordaron y mandaron que vaya vna persona que entienda de negoçios, y llebe poder bastante del concejo y testimonio de lo que pasa, y suplique al ylustrísimo señor don Juan de Abstria que se sirva de mandar que no salga desta villa gente de guerra, sino que quede'para la defensa della. Y para ello se enbíe vna persona a la cibdad de Granada, con poder a Antonio Martínez, residente en la dicha cibdad de Granada, para que io pida a el dicho señor don Juan de Aỉstrian. 
En 1.: ce noriembre ce $\mathbf{1 J 6 9}$, "äixeron que como ce los cadicios pásados cosia este concejo esta o bigacio... de ciar quarenta nor!bres para a guarra al ylustre señor :icenciado Marin de Carabajai, dei Consejo de sa magestad, y agora es venido a esta villa a el dicho efeto comisario particular y vara de justiçia vn Fulano Machüa, y para cumpir el dicho efeto $y$ obligación questá. fecha, señalaron de vna conformidad y vo. luntad los dichos quarenta horbres, en la forma siguiente:

Bartolomé Alviano,

Diego de Barea,

(Dos hijos de Sigura, pirtor, que son:)

Bartolomé de S.gura, y

Rodrigo de Sigura,

Cristoval Muñoz,

Luis Gómez, hijo de Martín Gómez,

Bartolomé de Bico,

Alonso Díaz, hijo de Antequera,

Diego de Lara, o su hijo,

Juan de Escobar,

Pedrosa, hijo de Baeça,

Pedro Amador, hijo de Bartolomé Gómez,

Bartolomé Martínez,

Cabrera, espadador,

Luis de la Mora,

Pedro de Bustos, el moço,

Alonso Sánchez, hijo de Gomes Sánchez,

Juan de Carmona, baezano,

Antonio de Esquinas,

Luis Gómez, hijo de Francisco Gomez Calbo,

Mateo Hortiz, hijo de Ugenio Ortiz,

Antón Bela de maese Guillén,

Francisco de Carmona, hijo de Juan,

Esteban, hijo de Alonso Gómez,

Alonso Amador, hermano de Antonio Amador,

Martín Sánchez, acarreador,

Leonís, 
Gonçalo Hernández, alnado de Martín de Salas,

Pero Mexía,

Alonso de Quesada, hijo de Mateo de Quesada,

Juan Martínez, tundidor,

Juan de Lara,

Pedro Ruiz, hijo de Juan Ramírez padre,

Pedro de Çamora, hijo de Çamora sastre,

Sancho de Canpos,

Antón de Canpo,

Juan de Cabedo,

Juan Pérez,

Gaspar Rodríguez, de Antón Martínez,

Pedro de Sigura, hijo de Sigura biuda,

El hijo de Gonçalo Calvo,

Alonso de Berenguel,

Vastián Cano, el moço,

Gonçalo Martínez, hijo de Francisco Martínez,

Francisco de Navarrete,

Juan Sánchez de Gregorio,

Pedro Martel, hijo de Bartolomé Mármol, hortelano,

Bartolomé Martínez, hijo de Bartolomé Enríquez,

Padilla, tundidor,

Sosiego,

Francisco Sala, hijo de Francisco Sala, en el Albaiçín.

„E ansí nonbrados, los mandaron apercebir para que vayan a servir a su magestad, como está mandado, y que vn algua(i) los aperciba para mañana, de en todo el día.

"En este dicho día, mes e año dichos, los dichos señores Quesada de suso declarados mandaron librar los mrs. siguientes: Mandaron librar a Alonso de Carmona, escrivano de su magestad, por lo que se ocupó en rrescibir la harina para enbiar a Guadix, dos ducados... A Gonçalo del Salto, personero desta billa... mandaron pagar veynte y quatro rreales de quatro días que se á ocupado en Cazorla, dos días con el i $i$ cenciado Caravajal, del Consejo de su magestad, para que no se saque gente desta villa... Mandaron librar a Gonçalo de 
Carmona, por vn mes que se ocupó en rrescebir quinientas fanegas de trigo $y$ hazellas harina para enbiar a Guadix, treyntá y dos rreales, y por la ocupaçión de su casa doze rreales. $Y$ a Juan Ruiz, por medir el trigo de la terzia, seys rreales".

En ə̀ de noviembre de 1569, "dixeron que para entregar los quarenta honbres questa villa tiene ofreçido para la guerra 2 $\therefore$ fecho las diligencias posibles para buscar arcabuzes, y an catado las casas de los vecinos desta villa y no án hallado; mandaron que para que en todo se sirva a su magestad que Francisco de las Nabas, personero desta villa, que va a Úbeda y Baeça a otros negoçios, procure çiento cinquenta arcabuzes, y haga el precio dellos y avise a esta villa para que se conpren, y los conçierte y ofrezca a dar çien ducados luego a la persona que los vendiere, y lo demás al plazo que conçertare, $y$ se le de ynstrucçión dello».

En el mismo día, el cabildo acuerda "que conpre el personero tafetán colorado, blanco y azul para vna bandera; y haga vna caxan.

En 12 de noviembre de 1569, "probeyeron lo siguiente: Lo primero dixeron questa villa ofreçió quarenta honbres armados a punto de guerra para servir a su magestad en la guerra del reyno de Granada, y por estos honbres á venido el capitán Pero VIéndez de Sotomayor... y el dicho capitán les pide les den a tndos los dichos honbres arcabuzes, y ellos con toda la diligencia y cuydado posible an buscado los dichos arcabuzes entre los vecinos desta villa y no han hallado más que catorze... los qua'es tienen para entregar a los dichos soldados, y para los demás darán lanças y ballestas, que son armas a punto de guerran.

Luego anota el escribano del cabildo: "Este día le notifiqué a el dicho capitán Pero Méndez de Sotomayor en persona, el qual dixo que requería y requirió a los dichos señores Quesada ciue luego cunplan con él dándole los dichos cuarenta honbres, conforme a la ynstrucçión del dicho señor don Juan de Abstria, ques armados a punto de guerra, que las dos. terçias partes arcabuzeros y la tercia parte de picas y vallestas".

En el mismo día 12 de noviembre de 1569, "dixeron que 
Gonçalo Machuca, alguacil executor del señor licenciado $\mathrm{Ca}$ ravajal, alcalde de corte, vino a esta villa a apremiar que los quarenta honbres questa villa of reçió para la dicha guerra; $y$ a estado en esta villa desde primero día deste mes, y dos días de benida y dos días de buelta, que son por todos diez y seis dias, y por el mandamiento del señor juez trae tasados treze rreales, mandaron que se le pague... que montan doçientos $y$ ocho rreales".

En el mismo día regresa de Andújar, Ubeda y Baeza el personero Francisco de las Navas, que "fué a Anduxar a negoçiar con el señor alcalde de corte, y le dió los despachos que lleuava, y truxo otros para el señor don Juan de Abstria y para este concejo». En la rendición de cuentas dice que "confró vna caxa y le costó tres ducados... Yten conpró nuebe varas de tafetán blanco y nuebe de amarillo y nuebe de morado y tres de colorado, para la bandera. Yten conpró dos onzas de. seda morada para coser la bandera".

Malas noticias debió traer el personero, pues en el mismo cabildo, "dixeron que porque por mandamiento del señor licenciado Caravajal van presos a Anduxar los dichos señores alcaldes, mandaron que vaya con ellos Francisco de las Navas, personero, y que se vayan por Jódar y cobren cartas del señor don Alonso de Caravajal. $Y$ para el absencia de los señores alcaldes dieron poder y facultad cunplida a los señores Pedro Tribaldos y Hernando de Alcalá del Coso para que vsen y exerçan los dichos ofiçios de alcaldes hordinarios desta villa, que para ello les dieron poder en forman.

En 13 de noviembre de 1569, los capitulares "mandaron que atento el peligro de los moros, questá en las manos, y entran $y$ an entrado a los términos desta villa, que se bele y guarde esta villa y término della, y para ello estén en la torre de Tiscar tres honbres, y en la torre del puerto de Tiscar otros tres honbres, y en el castillo de la Madalena otros tres honbres, y que si en la torre de Lacra ya oviere dispusición de poderse belar se pongan otras tres personas; y questos den... aviso si alguros moros ouieren a entrar, y hagan humadas por horden de guerra. Que se guarde esta villa, y tenga cuidado dello el señor 
Bartolomé Martínez, rexidor y capitán, el qual, juntamente con los señores alcaldes e regidores, nonbre sus guardias para ello. Y que a las personas que fueren aperzebidos para hazer centınela y no estubieren apercebidos, que el dicho señor capitán ponga otro honbre en su lugar y se le pague de la hazienda del que faltara estando aperzebido. Y que se pregone públicamente questén todos los vecinos a la horden del dicho capitán. Así mismo mandaron pregonar que se hagan quadrillas y se barreén las calles y portillos; y que los vecinos... que fueren apercebicos para las dichas quadrillas se estén apercebidos siempre, de seisçientos honbres".

En 14 de noviembre de 1569, "mandaron quel superior del monesterio del señor San Juan desta villa baya a Granada, a llevar los ynformes questa villa á fecho sobre los rebatos que cada día ay, y a ynformar al excelentísimo señor don Juan de Abstria de la necesidad que esta villa tiene de gente".

En 19 de noviembre de 1569, mandaron que Juan Moreno, que va a la corte, "llebe las ordenanças questán hechas sobre la guarda de la sierra e término desta villa, para que su magestad las confirme". También "mandaron que se pregone que todos los postigos y bentanas de las çercas desta villa se çierren dentro de terzero día, so pena que se mandarán cerrar a su costa y se les llevará de pena doçientos mrs. para los gastos de la vandera y caxa y guerra. Mandaron que se pregone... que ringún vecino desta villa, ni de fuera della, después de noche 1io tire arcabuz ni tiro de pólbora si no hubiere causa para tocar arma, so pena que tenga perdido el arcabuz o tiro... Otrosí, rıandaron que mañana, domingo, se haga reseña".

"Yten mandaron que cada vecino desta villa, quando le tocare el mandado del capitán, dé vna carga de leña para las noches que se tenga lunbre en el cuerpo de guardia; y que se tenga en cada cuerpo de guardia en cada noche una carga de leña. Yten nonbraron por capitán de la gente de caballo desta villa al señor Antonio Martínez, regidor desta villa... y quel dicho señor Antonio Martínez tenga cuidado de la guarda del alcaçar desta villa... Yten mandaron que salgan a correr la tierra seys honbres que sean personas expertas para ello; y que 
a estos y a los que estubieren en las atalayas se les dé tres ducados a cada vno y una hanega de trigo cada mes».

En 26 de noviembre de 1569, mandaron "que se le dé a Benabente, sastre, y Ana Martínez, vecinos desta villa, por el cortar y coser de la vandera desta villa tres ducados y medio... Señalaron por comisario para barrear la calle que sale al barranco del exido al señor Fernando de Alcalá, alcalde hordinario... para barrear la caua y la puerta la Orca... y la calle de la puerta de Úbeda.

"Los señores alcaldes dixeron que en virtud de vn rrequerimiento que se les á fecho por los señores rregidores para que enbien a Guadix las quinientas fanegas de harina que rrestan para las mill fanegas que an de enbiar para el exército de su magestad... mandan que trecientas fanegas de trigo questán en Foder de Ximón López... se hagan harina con toda diligencia y cuydado; y que en el entretanto que se hazen darán horden d $\epsilon$ dónde se saquen las docientas fanegas que faltan".

En 1. ${ }^{\circ}$ de diciembre de 1569 , "bieron vna petiçión de Diego de Bargas, que va con el artillería del señor marqués de Camarása a Huéscar, pidiendo se le dé escolta para pasar adelante con el artillería, y significando la obligación en que esta villa está al duque de Alba, y pidiendo se le presten cinquenta ducádos por ocho días, para pasar adelante. Dixeron que abida consideraçión a la buena voluntad que el señor duque de Alba a mostrado tener a esta villa, que aunque esta villa tiene mucha necesidad de gente le mandan dar ocho escuderos y beynte tiradores que le hagan escolta hasta Guadalentín; y que el señor Bartolomé Martínez, capitán desta villa, baya y buelba con la gente que fuere de escolta".

"Que baya Francisco de las Nabas, personero, a Caçorla, y trate con Juan de Coria que trayga para esta villa çien arcabuzes, o çiento cinquenta, y que se le dará siguridad para ello. $Y$ que llebe la probisión para quel señor Alcalde de corte no saque escuderos desta villa, y la consulte con el licenciado Pérez, para que dé el horden que se á de tenern.

En 2 de diciembre de 1569, "mandaron que porque se le á ofreçido a Sedeño, probeedor del canpo del marqués de Belez, 
escolta para pasar hasta Guadalentín, que se les notifique que bayan con él los escuderos siguientes: Cristobal Rico, Pedro Faz de Poyatos, Alonso Amador, Vastián de Alcalá, Castilla el biejo, Juan de Poyatos, Melchior de Peralta, Pedro Polayno, Francisco de Lara, Lázaro de los Rios, Bartolomé de Poyatos, Diego de Bustos. A los quales mandaron se les notifique a cada vno de por sí questén apercebidos y vayan por la mañana con sus armas y cauallos para el dicho biage, y para correr la tierra, y lo cunplan so pena de mill mrs. y diez dias de prisión. La pena para gastos de guerra... Que se pregone... que por la mañana salga la gente de a pie y de a cauallo desta villa a correr la tierra, con los capitanes dellan.

En 5 de diciembre de 1569, mandaron "que Francisco de las Nabas... vaya a Andújar, y requiera al señor Alcalde de corte Caravajal con la probisión questa villa tiene para que no se saque gente desta villa, y por la horden que á dado el licenciado Pérez, letrado desta villa».

En 6 de diciembre de 1569, “bieron vna petición de fray Luys cie Prados, superior de conbento de señor San Juan, que fué por horden deste concejo a Granada, a pedir que no sacasen gente desta villa para la guerra, y otra probisión para que los ganados desta villa entren en los términos de la comarca. Y le mandaron librar mill docientos mrs. de gasto que á fecho, y quatro ducados, con los seis que se le dieron... Que se le den a Alonso de Çamora seis rreales por lo que se ocupó en hazer la harina para Guadix".

En 12 de diciembre de 1569, "dixeron que por quanto en esta villa está vn capitán con seysçientos honbres poco más que menos, que va al servicio de su magestad a la guerra del rreyno de Granada, y dize que no se atreve a yr de aquí a Çújar por llevar la jente desarmada, y destarse aquí los vezinos rresçiben grande vejaçión, que mandavan que desta villa vayan diez o doze de a cavallo ponellos en salvo. $Y$ que vaya con la jente desta villa el señor Bartolomé Martínez, rregidor desta villa, ques capitán señalado para la guarda del término desta villa".

En 13 de diciembre de 1569 , "acordaron que porque esta villa es frontera del reyno de Granada y los moros bienen cada día 
a correr el término desta villa y llevarse cavtivos y ganados, $y$ tienen nonbrados capitanes y alferez y sargentos y otros ofiçıales de pie y de cavallo, y para la defensa desta villa se han fecho y facen gastos y es neçesario se hagan cada día, que mandaron se enbie desto ynformación al Consejo Real", pidiendo que se paguen de los propios, o se repartan. También "tomaron quenta a Francisco de las Navas, que fué ( $i$ Andújar) a requerir con vna provisión que llevava del señor don Juan de Abstria para que no sacasen la jente desta villa».

En 23 de diciembre de 1569, "vieron vna carta dei señor Comendador mayor, e mandaron que se escriva vna carta en respuesta, y que vaya vn rregidor con dicha cartan.

En 24 de diciembre de 1569, "vieron vna carta del señor Alonso Hernández Delgado, provehedor del campo de Guadix, $\in n$ que pide por ella que se le enbien las quinientas fanegás de harina que se deven y dize que se le restan deviendo de las mill fanegas que dizen que ofresçió esta villa. $Y$ mandaron que se le rresponda por carta cómo no ay más que trezientas fanegas, y que con las demás se alçó el marqués de Camarasa; y gue estas trezientas fanegas no se an podido hazer harina, por. grandes oqupaçiones que á avido. $\mathrm{Y}$ que por el señor alcalde Salazar está rregistrado todo el trigo y bituallas desta villa, y bagajes; y que ansí no se puede enbiar. Y que demás desto se escriva que por orden del dicho alcalde y del Comendador mayor está esta villa a orden de Baça y no a la de Guadix, y ansí los proveymientos que desde esta villa an de salir está mandado por el dicho alcalde que vayan a Baça. $Y$ que se le enbie vn traslado signado de la dicha carta del Comendador mayor. $\mathrm{Y}$ mandaron que sin enbargo desto se hagan las dichas trezientas fanegas de trigo, e se pongan en lugar cónmodo, para que della se haga lo que convenga. $Y$ que se traigan los molineros y se les notifique que en el plazo muelan con quenta y rrazón, so pena de diez mill mrs. para la cámara de su magestad.

"Mandaron se le libren a Blas Ortega y Juan de las Navas, alférez que son, y Alvaro de Baeça, sarjento de las guardas y çentinelas desta villa, a cada vno quatro ducados, en el mayor- 
domo del concejo, por orden de gastos de guerra, pues ques regoçio que conviene al serviçio de su magestad y a la buena conservaçión desta villa. Mandaron librar a Francisco de las Navas, personéro desta villa, diez y seys rreales, dè dos días que se ocupó en yr a Ubeda a negoçiar con el señor alcalde Salazar sobre el rregistro que mandava hazer en esta villa; y quatro rreales que dió a vn letrado para que proveyese vn auto er: el pleito con Texerina que se trata con el concejo sobre las tierras de Guadalentín'.

En otro cabildo del mismo día 24 de diciembre de 1569, "acordaron que los señores Antonio Martínez y Juan de Alcalá, regidores desta villa, vayan a la çibdad de Baça, a hablar al y'ustre señor don Luys de Requesens, comendador mayor de Castilla, y que le agradezcan y besen las manos en nonbre desta villa por la carta del buen comendador en questuvo de enbiar a esta villa sobre la horden que se á de tener en el escoltar los bastimentos y asigurar la tierra de aquí a Çújar; y que sepan si la jente de escolta á de pagarse del concejo y fropios, o si la á de pagar su magestad. Y que les haga merced il esta villa, por no tener armas, dozientos o trezientos arcabuzes; y que asienten el presçio y plazo que se pueden dar, porque dándole a esta villa armas se guardará con muy grande diligençia.

"Mandaron que se haga harina las trezientas fanegas de trigo que quedan de las mill fanegas que se of resçieron al provehedor de Guadix; y que den ochenta libras de harina los :nolineros de cada vna fanega, porque ansí está fecho el ensayo.

"Mandaron que se haga alarde de jente de cavallo y de pie, para mejor ynformar de la jente de guerra que ay en esta villa ; $y$ que se alisten con las armas y cavallo por ante escrivano que tome lista; y se les aperciba que salgan a las escoltas como les fuere mandado. Mandaron que se ponga los atalayas y espias, como está mandado, porque los moros andan salteando en el término desta villa; y que se asienten las esquadras por ante escriuano del cabildo, para que los apremien a que salgan a las escoltas. Pregonóse que saliese la jente al alarde con sus 
armas, so pena deyscientos mrs., aplicados a gastos de guerra y que se procederá criminalmente».

En 2 de enero de 1570, “mandaron que andando junto al ganado de vezinos desta villa, aunque sea de dos o tres dueก̂́os, que todo sea vna manada e se pague por vna denorninación".

En 3 de enero de 1570, “aviendo entendido lo que los señores Antonio Martínez y Juan de Alcalá, regidores, an tratado acerca de las escoltas, mandaron que sobre lo que se trató con el señor Comendador mayor de Castilla que de causa que de hazerse por esta villa escolta a esta villa se le sigue mucho daño y que no la puede sufrir, por los muchos gastos que esta villa á tenido y por los pocos propios que esta villa tiene, que vaya persona desta villa a suplicar al serenísimo señor don Juan de Abstria y con su exçelençia el señor Comendador mayor que no manden questa villa haga escolta, porque no la puede sufrir. $Y$ que en caso que no aya lugar dexarla de hazer, se inande que se les asigne paga por S. M., como a las demás gentes de guerra que le sirben, pues es serbiçio de S. M. y que ynporta la escolta tanto.

"Y que entretanto que esto se trata, porque no aya falta en el serbiçio de su magestad, mandan que se haga escolta por esta villa, y que salga a la mitad del camino, que es a los $\mathrm{Hi}$ nojares, y lleguen al rostro del canpo a la cañada de Sancho Gómez. Y que cada escolta salgan desta villa diez escuderos y çinquenta tiradores, y de allí arriba, a la horden del señor capitán Bartolomé Martínez. Y que las escoltas sean lunes, miércoles y biernes de todas las semanas, y que se prinçipie desde mañana miércoles... Ansí mismo mandaron que por quanto los dichos señores regidores traen resoluçión de su excelencia el señor Comendador mayor de Castilla que se darán a esta villa çierta cantidad de arcabuzes, y que dexan librança de los que an de dar en poder de Çabala, ques quien tiene a cargo la muniçión, que mandan que la persona que fuere a tratar de lo de las escoltas llebe poder desta villa para obligarla por la cantidad que montaren los dichos arcabuzes, y a los plazos que por 
su excelencia se mandaren dar y se le ordenare para el señor alcalde de corten.

En el mismo día, "mandaron que vaya a Baça, a tratar con el serenísimo señor don Juan de Abstria y con su excelençia el Comendador mayor de Castilla, sobre el horden del escolta y sobre lo de los arcabuzes, a Hernando de Alcalá, vecino desta villa).

En 6 de enero de 1570, “mandaron que por quanto está tratado que entretanto que se probeé por su alteza el señor don Juan de Abstria sobre lo del escolta, que se haga escolta lunes y miércoles y viernes, y porque oy biernes se abía de hazer escolta, e de causa que salió el miércoles y corrió la tierra, y quitó vna cabalgada de mill quatroçientas e çinquenta cabeças de ganado lanar, e mataron tres moros, y quitaron vn cautibo, y al presente ay nesçesidad de que se haga escolta en cunplimiento de la carta de su magestad que escribió al corregidor de Eaeça, por que se aconpañase Don Luys de Ayala, de la boca ce su magestad, para que se lleben los vianderos que llevan bástimentos al canpo de Baça, por tanto mandaron que salgan a la dicha escolta hasta los Hinojares diez escuderos de a caballo y çinquenta peones tiradores, y que la gente de caballo llebe cargo della Cristobal de Lorca. Y mandaron se notifique a todos los contiosos que no tienen caballos para serviçio de su magestad los conpren y tengan dentro de tercero día, con aperçibimiento que les benderán sus bienes y a su costa los conprarán, y mas les esecutarán por diez mill mrs. para los gastos de la guerra, e pondrán escuderos que sirban a su costan.

En 10 de enero de 1570, "mandaron que Ximón López, depositario, preste 439 rreales, que se los dé al arçipreste para le Fagar el trigo que se le tomó para llevallo al rreal de su magestad del reyno de Granada. Y que acabado de llevar toda la harina se le bolberán a pagar o se le librarán".

En 11 de enero de 1570, "dixeron que por quanto por previsión del serenísimo señor don Juan de Abstria se les manda lleven desta villa con mucha guarda el dinero que tiene en esta villa Su Magestad para el exército de la çibdad de Baça y reyno de Granada, y esta no es escolta ordinaria; y conviene que 
sc pague alguna ayuda de costa, mandaron se libren en los. propios desta villa 138 rreales... Dixeron que por cuanto ban a la dicha escolta a la çibdad de Huéscar y tardarán poco tiempo, y conviene que en el interin es nescesario que queden alcaldes... que nonbran por tales alcaldes a los señores Pedro 'Iribaldos y Sevastián de Alcalá".

En 21 de enero de 1570, "dixeron que en esta villa ai çiesn arcabuzes en poder del capitán Bartolomé de Aranda, los quales á dado el excelentísimo señar don Luys de Requesens, comendador mayor de Castilla, para que se repartan en esta villa entre los vecinos della, mandaron questos se tomen y se repartan entre las personas que se señalaren para la escolta... al precio que por su magestad y por el dicho señor Comendador se cargaren a los demás soldades de sus exérçitos". Y luego: "Este día rescibieron del dicho capitán Aranda los dichos çien arcabuzes, con sus frascos.

"Que se le notifique a Fernando de Mata y Gonçalo del Salto, depositarios y fiadores que son de los quarenta ducados. que se prestaron a Diego Vargas para llevar el artillería, que luego los den, pues el dicho Diego de Bargas los á entregado. $Y$ si no los dieren luego los prendan y les vendan sus bienes, como depositarios. Y luego que los den, vaya Juan Moreno'a corte a llevarlos a Juan Baptista, soliçitador desta villa, en el entretanto que ba Francisco de las Nabas, personero, a corte."

En 24 de enero de 1570, "dixeron que yendo ayer la escolta desta villa a llebar las muniçiones y dineros de su magestad, descubrieron doçientos moros en las Cañadillas, término desta villa, y para sigurar la tierra hes necesario que aya espias que vean los moros y den abiso. Mandaron que se pongan dichos espias en término desta villa, y se les pague a tres reales cada cía a cada espían.

En 2 de febrero de 1570, «mandaron librar a... por nueve dias que se ocuparon en Huéscar en dar el asiento con si alteza el serenísimo señor don Juan de Abstria sobre la escolta questa villa haze... Yten mandaron librar a los señores Antonio Martínez y Juan de Alcalá, regidores, a cada vno dellos quarenta reales, de çinco días que se ocuparon de ir a Baça 
y comunicar con el señor Comendador mayor de Castilla y con el señor Muñetones, porque diesen arcabuzes a esta villa... Mandaron que Luis de Carrión, vecino desta uilla, baya a Huéscar, a que se den dineros a esta uilla para pagar las escoltas que haze, y se les escriva al señor Comendador mayor y al serenísimo señor don Juan de Abstria y al señor Alcalde de corte, y lleue ynstrucción de lo que á de hazer, y testimonio de lo que se á gastado en las pagas de las escoltas. $Y$ que pida las bolsas y moldes de los çien arcabuzes, que faltaron en ellos».

En 8 de febrero de 1570, "mandaron que por quanto án sido requeridos con dos çédulas, la vna de $\mathrm{Su}$ Magestad y la otra del serenísimo señor don Juan de Abstria para que tenga esta villa tres caballos para correr la posta, y porque se sirba $\mathrm{Su}$ Magestad con toda diligençia y cuydado, mandaron que se busque en esta villa y en la villa de Caçorla los dichos tres caballos, y que se pregone sy ay personas que los quieran tener alojados para el dicho efeto vengan ante sus mercedes a hazer la obligaçión y le darán las costas. E si no hubiere persona que los quiera tener, para que no aya falta en el serbiçio de Su Magestad mandaron que de los bienes e propios desta villa se conpren los dichos tres caballos para el dicho efeto, e se ponga luego en efeto lo suso dicho con toda diligençia y cuydado. Y mandan que Ximén López, vecino desta villa, tenga cargo oe hazer las dichas diligençias, con todo cuydado, y se le pagará el trabajo y ocupaçión como sus mercedes viesen que es juston.

En 9 de febrero de 1570, "dixeron que como es notorio esta villa está muy a peligro de moros y conbiene se guarde con recato y vigilancia; y señalaron para la guarda de las puertas del alcáçar della a Gonzalo de Alcalá, vecino desta villa, al qual mandaron entregar las llaues de las dichas puertas, y cue las çierre a las diez horas de la noche y las abra cuando amanezca. $Y$ se le señalaron de salario por cada vn mes quinientos mrs., y gane el dicho salario desde oy. $\mathrm{Y}$ tiene de dormir en las casas del cabildo desta uilla, para questé más a funto para lo que sucediere... Yten mandaron que porque Luis de Carrión, vecino desta villa, que estaua mandado para ir por 
dineros a Huéscar para las escoltas, no á dado fianças para ello, que vaya por los dichos dineros el señor Antonio Martínez, regidor".

En 11 de febrero de 1570, "tomósele quenta a Francisco Bela, herrero, de la obra de hierro que á fecho para las puertas de la villa".

En 23 de febrero de 1570, "tomaron quenta al señor Antonio Martínez, ... de la ynstrucçión que llevó. En quanto el primero capítulo, que se le mandaba que diese las cartas al serenísimo don Juan de Abstria, dixo que las dió, e mostró vna carta del Comendador mayor, y que trae dozientos ducados en bista dellas para pagar la jente de guerra de las escoltas. En quanto al segundo capítulo, dixo que le respondió que no á lugar. En quanto al tercero capítulo, dixo que pidió las bolsas e moldes de los arcabuzes, y le respondieron questaban en Guéscar".

En 24 de febrero de 1570, "tomósele quenta a Juan Baptista escrivano de la yda que fué a corte de $\mathrm{Su}$ Magestad a negoçios deste concejo... De escrebir el prebillegio de la uilla en pe: gamino, cien reales... De siete pliegos de pergamino que con.fró, catorze reales... Quatro ducados que pagó al secretario Escobedo, por el pribillegio que truxo desta villa".

! En 27 de febrero de 1570, "mandaron que vayan... al rreal del excelentísimo Don Juan de Abstria, a traer dineros para la gente de la escoltan.

En 5 de marzo de 1570, "mandaron que Francisco Vela, vezino desta villa... llebe las picas que tiene $\mathrm{Su}$ Magestad en esta villa al tenedor de las muniçiones de Su Magestad en Baça... y quel dicho Francisco Vela pueda apremiar a todos los vecinos desta villa que tienen bagajes para llebar las dichas picas, por quanto el serenísimo señor don Juan de Abstria las manda llebar con toda brebedad... Mandaron que se escriba a. Juan Bautista que saque probisión para que el Concejo libre los gastos que se an hecho en las cosas de la guerra, y días que se an ocupado sus mercedes quando los llebaron a Huéscar para que se obligasen al hacer del escolta".

En 11 de marzo de 1570, "tomaron quenta a Juan Bautista 
dє ia yda que í a Baça... En quanto al primero capitulo, que se le mandó pidiese provisión para que no se sacase pan amasádo desta villa, dixo que trae (cédula) del licenciado Salazar, cel Consejo de Su Magestad, para que no saquen pan amasado desta villa, so ciertas penas... En quanto al sigundo capítulo, que se le mandó diese querella del capitán don Jerónimo, dixo que presentó la ynformación y petiçión que llevava, y se mandó dar juez para que viniese el negoçio por ante Peḍro de La Fuente; y por no llevar poder y prouisión para traer el juez no lo truxo... En quanto al terzero capítulo, que se le mandó fidiese dinero para las escoltas de esta villa, dixo que se le mandó dar trecientos ducados... En quanto al quarto capítuio, que trata que pidiese las bolsas y moldes a Galarça, dixo que trae sesenta moldes para los arcabuzes, y que trae çertificación del dicho Galarça de cómo no hubo más muniçión.

"En quanto a lo que se le dixo de palabra, que pidiese que los vecinos desta villa se viniesen, porque avíe falta de gente ae la escolta, que presentó la provisión que llevava, y que trae mandato del avditor general, en cunplimiento de la provisión, que se bolbiesen... Madaron se le libren a Gonçalo de Alcalá... del vn mes que á servido e tener quydado de çerrar las puertas del alcáçar... Vieron vna carta del serenísimo señor don Juan de Avstria, en que dize que se tiene mucho desquydo en enbiar los panes, que les hordena que de aquí adelante tengan grande quydado de fazellas enbiar, porque de no enbialla con gran diligençia caherán en su desgracia».

En 27 de marzo de 1570, "dixeron que por quanto a causa de los muchos enfermos que bienen de Baça y otras partes de enfermedad contagiosa se á pegado enesta villa y mueren muchas personas, y no caben los espitales ni tienen con qué curallos, y ay necesidad de remediar esto, y para obrallo, manciaron que se (ponga) vn alguazil que esté en la benta de Poyato, término de esta villa, para que no dexe pasar ninguno a esta villa".

En 2 de abril de 1570, "dixeron que por quanto los dineros del escolta se an acabado, e se deben tres escoltas, y ay neçesidad de ir a Baça por dineros, acordaron que vaya a ello el 
capitán Bartolomé de Aranda, y hable al señor don Juan y al señor Comendador mayor, y trayga dineros, y pida que se le de probisión para que las conpañias no estén en esta villa riás de una noche, y traiga orden de todo... Otrosí, dixeron que por quanto en dicho día llego a esta villa una carta del serenísimo señor don Juan de Abstria, pidiendo que se le probeyese de pan amasado, mandaron que se le responda luego y que se amasen docientas fanegas de pan".

En 4 de abril de 1570, "mandaron que con el pan questá amasado para llebar al exército del serenísimo señor don Juan de Austria baya un onbre, que baya con ello con el capitán Bartolomé de Aranda; lo que le cometieron".

En 9 de abril de 1570, "mandaron que entre los señores alcaldes i regidores 'se den... quarenta mulas para llebar las çien fanegas de pan amasado queste regimiento á mandado amasar para llebar al exérçito del señor don Juạn, y se apremien todos a ello; y que para esto se junte todo el pan amasado en casa de García de Carmona... Mandaron que se pregone que a tanto que en tanto que aya mulas y moços, que todos bayan .al escolta, con todas sus armas, y no bayan muchachos... Mandaron que bayan el capitán Bartolomé Núñez, (que) vaya con quatro escuderos a reconocer la tierra".

En 20 de abril de 1570, “el señor Bartolomé Martínez de Carmona, regidor e capitán de la escolta desta villa, dixo que va sus mercedes saben cómo ay nueba çierta que en el término desta villa ay moros, y que el canpo está lleno de ganados y gente, ay necesidad de correr la tierra y descubrir quántos ay: y que pedía y requería a los señores alcaldes y regidores que lc den gente y bastimento para tres días, quél quisiera yr y correr la tierra y aseguralla, con protestación que si no se le diesen luego como lo pide y algún daño o perjuicio biniese a esta villa y sus vecinos, sea culpa y cargo de los dichos señores y no al suyo; y lo pidió por testimonio.

"Y los dichos señores alcaldes y regidores mandaron quel dicho capitán baya y corra la tierra, y reconozca los moros, y qué jente ay, y llebe ciento y cinquenta tiradores y doce caballos, y que no vaya sin ellos y con todo recato y diligencia. 
Y reconozca lo que ay; y si fuere neçesario de socorro dé abiso a esta villa para que le socorran; y oy él que no entre donde se pierdan él y su jente, sin entender lo que conbiene. $Y$ que para ello se le den trezientos panes y vna carga de bino y media arroba de azeite. Y mandaron que del dinero que sobró del pan que se sacó para llebar al real... se conpre el dicho pan, y que Pero Núñez lo pague: si de presente no hubiere, se tume de aquellos y se le de librança".

El 6 de mayo de 1570, "mandaron librar en Ximén López, depositario de los mrs. de la jurisdición, docientos ducados para єi abasto de Baçan.

En 9 de mayo de 1570, «mandaron que vaya vna persona de confianza al real del señor don Juan, a traer dinero para las escoltas que haze esta villa por mandado de Su Magestad, porque no ay dinero para pagar gente... Mandaron que Franc sco Vela de quenta del dinero que traxo de las çien hanegas de trigo que llebó en pan ázido al real".

En 16 de mayo de 1570, "dixeron que por quanto el conceio trató pleito con Bernardo (?) de Lorca, sobre abasto de carne de Baça, e agora se á tratado concierto con él, que como se les presten 200 ducados se le presten 300 ducados hasta el día de Todos Santos... Mandaron que las guardas que están puestas en esta villa no guarden el Eredamiento ni nada del arbolado, ni puedan denunciar, y que solamente guarden... Dixeron que por quanto está mandado quel capitán Aranda baya por dineros para la escolta... le asignen salarion.

\section{J. DE M. Carriazo}

(Continuará.) 